\title{
UTILIZAÇÃO DE ANALOGIAS EM SEIS LIVROS DIDÁTICOS DE QUímica APROVAdos No Programa Nacional do Livro DidÁtICo 2018: UMA ANÁlISE SOBRE ESTRUTURA ATômicA
}

USE OF ANALOGIES IN SIX CHEMISTRY TEXTBOOKS APPROVED IN THE PROGRAMA NACIONAL DO LIVRO DIDÁTICO 2018: AN ANALYSIS OF THE ATOMIC STRUCTURE

DOI: 10.23926/RPD.2526-2149.2020.v5.n2.p1019-1039.id687

\section{Leandro de Oliveira Amaral \\ Mestrando em Química pelo Programa de Química Pura e Aplicada (UFOB) \\ leandroamaral368@gmail.co $\underline{\mathrm{m}}$}

\section{Sérgio Macêdo Soares Doutor em Química (UnB) Professor na Universidade Federal do Oeste da Bahia (UFOB) \\ sergio.soares@ufob.edu.br}

\section{Mayara Soares de \\ Melo \\ Mestra em Ensino de \\ Ciências (UnB) \\ Doutoranda no Programa de \\ Pós-Graduação em Educação em Ciências (UnB) \\ Professora na Universidade \\ Federal do Oeste da Bahia (UFOB) \\ mayara.melo@ufob.edu.br}

\begin{abstract}
Resumo: Neste artigo são apresentadas dezesseis analogias encontradas no conteúdo de estrutura atômica em seis livros de Química aprovados pelo Programa Nacional do Livro Didático (2018) destinados ao ensino médio. Após a identificação, as analogias foram categorizadas e observaram-se deficiências quanto ao formato, nível de enriquecimento, abstração e limitações, sendo utilizadas apenas de maneira superficial. Foram explorados os possíveis erros conceituais que essas estratégias podem levar quando abordadas de maneira inadequada. Os resultados indicam que as analogias do pudim de passas, panetone e do sistema planetário pouco contribuem para o entendimento do conceito-alvo e podem levar a compreensões equivocadas e superficiais. Além disso, estão ausentes discussões mais acentuadas tanto das relações analógicas quanto das limitações entre os domínios. Também são discutidos apontamentos adequados sobre o uso dessa estratégia.
\end{abstract}

Palavras-chave: Analogias. Livro didático. Estrutura atômica.

\begin{abstract}
The article presents sixteen analogies found in the content of atomic structure in six Chemistry books approved by the Programa Nacional do Livro Didático (2018) for high school. After identification, the analogies were categorized and deficiencies were observed in terms of format, level of enrichment, abstraction and limitations, being used only superficially. The possible conceptual errors that these strategies can lead when approached inappropriately were explored. The results indicate that the raisin, panettone and planetary pudding analogies contribute little to the understanding of the target concept and can lead to mistaken and superficial understandings. In addition, more pronounced discussions of both analogical relations and limitations between domains are absent. Appropriate notes on the use of this strategy are also discussed.
\end{abstract}

Keywords: Analogies. Chemistry books. Atomic structure. 


\section{INTRODUÇÃO}

Um dos grandes problemas observado pelos professores no ensino de Ciências é a dificuldade que os alunos têm para compreender alguns conceitos, notadamente, aqueles que exigem maior grau de abstração. Para minimizar essas dificuldades e mediar a apropriação do conhecimento, esses profissionais têm utilizado diversos recursos no processo ensinoaprendizagem, dos quais emerge como destaque o grande uso de analogias (OLIVEIRA, 2012).

Professores têm utilizado analogias com bastante frequência no ensino de Ciências com o objetivo de se beneficiar do caráter macroscópico dessa estratégia e tentar facilitar a compreensão de fenômenos ou situações em que apenas a descrição do conceito científico não o torna claro. A ideia central dessa estratégia é fazer uma relação sistemática de duas situações distintas: uma já conhecida, estabelecida e de total compreensão por parte da pessoa (domínio análogo), e outra completamente nova (conceito-alvo), a partir da qual busca-se desenvolver um processo de lógica do que é ensinado considerando-se as semelhanças (relações analógicas) entre as duas situações (Figura 1) (FRANCISCO JR., 2010; OLIVEIRA, 2012).

Figura 1 - Esquema representacional dos domínios análogo e alvo

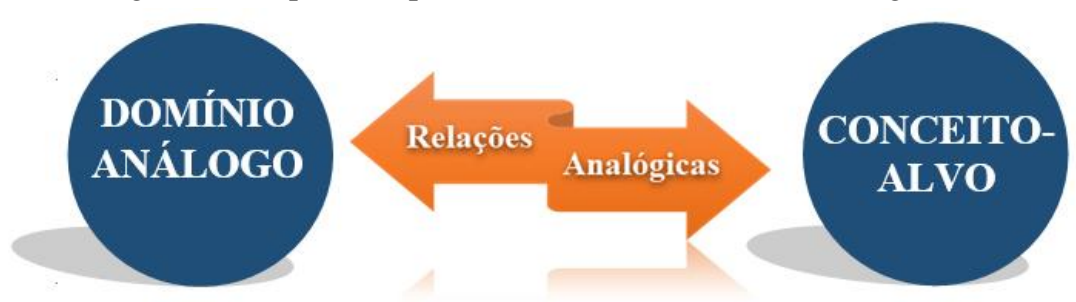

Fonte: Elaborado pelos autores

Diante desse aspecto, o emprego do termo "semelhanças" acaba sendo muito abrangente e inclui outros conceitos como metáforas, exemplos e assimilações, os quais podem, muitas vezes, ser considerados erroneamente como analogias (FRANCISCO JR., 2010). Nesse sentido, as definições atribuídas para analogias tentam retratar a ideia de uma comparação explícita (aquela que contém o termo comparativo). Segundo Gentner (1989) e Aulete e Valente (1974), a analogia é consequência da comparação de novos termos com outros que já são conhecidos ou familiarizados. Nela, ao se compararem as semelhanças das coisas, pode-se levar ao entendimento da razão dessas relações e semelhanças. Já Duit (1991) e Mól (1999) relatam que analogias e metáforas comparam as semelhanças entre os dois domínios e a diferença básica entre esses dois conceitos está na clareza com que as relações analógicas são colocadas.

No âmbito da Química, a utilização de analogias e metáforas como estratégia de ensino é bastante grande e pode ser exemplificada pelo emprego corriqueiro dos termos clássicos como "gases nobres”, “famílias de elementos”, “blindagem de núcleo”, “semelhança ao pudim de 
passas" e "nuvem eletrônica" (FERRY; NAGEM, 2009). A natureza abstrata e complexa de muitos conceitos básicos faz com que professores e autores de livros didáticos utilizem esse tipo de estratégia a fim de tornar mais compreensível a explicação de conteúdos de Química. Bozelli e Nardi (2006) demonstram que essa linguagem tem se apresentado como uma alternativa atrativa pelos educadores para propiciar aos estudantes uma compreensão maior das novas informações que lhes são ensinadas.

Entretanto, é importante frisar que, apesar de ser uma alternativa auxiliadora, o uso das analogias pelos professores e livros didáticos requer certa atenção para que não resulte em conclusões equivocadas. Isso porque, a depender do modo como se utiliza e da forma como se expõe, elas podem levar a compreensões incorretas dos conceitos, sendo estes entendidos de forma simplificada e guiando o pensamento para uma visão superficial que é distinta daquilo que o próprio conceito-alvo retrata (RAMOS; MOZZER, 2018).

A título de exemplificação, na Figura 2 é apresentada uma analogia encontrada em um livro didático da década de 1980. Para explicar a alotropia do carbono, utilizou-se de uma analogia para distinguir a forma de organização estrutural do carbono na sua forma grafite e diamante, respectivamente (SILVA; SILVA, 1980). A analogia destaca o carbono grafite associado a uma representação de um homem negro, descalço e com os braços cruzados atrás das costas, enquanto o carbono diamante é representado por uma mulher branca, com roupas longas e usando joias. Conforme observado na imagem, há uma manifestação racista, que coloca o povo negro em posição de inferioridade, expressa em um livro didático.

Figura 2 - Analogia utilizada em um livro didático de 1980 para a distinção da forma de organização estrutural do carbono na forma de grafite e diamante

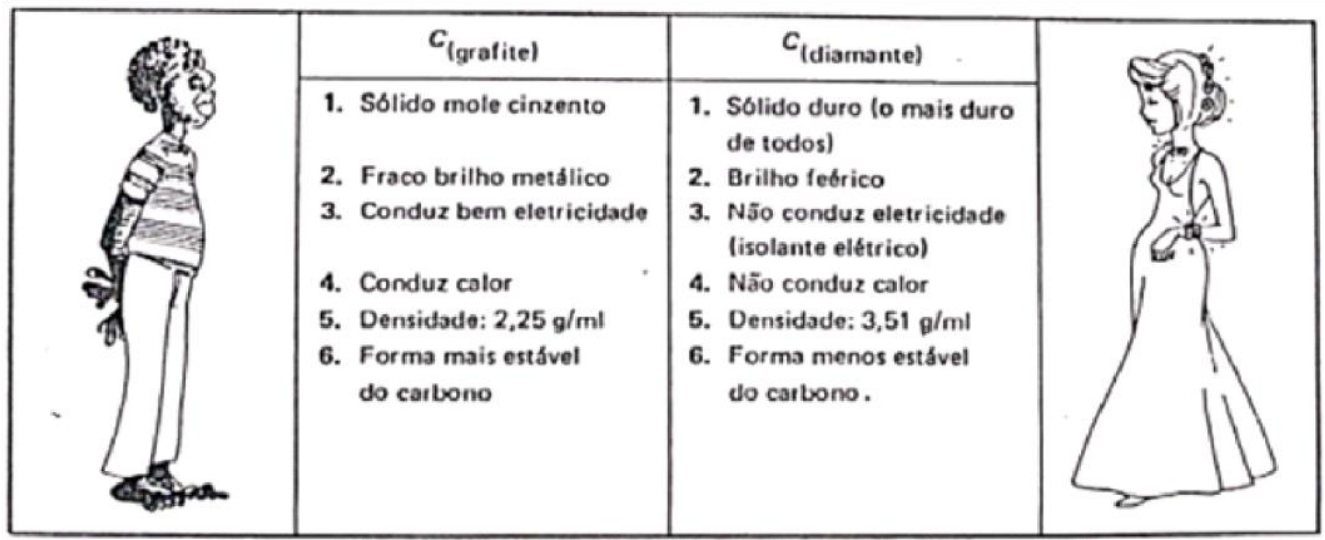

Fonte: Silva e Silva, 1980, p. 200

Diferentemente disso, espera-se que o livro didático enquanto uma das principais ferramentas usadas por professores e alunos apresente as informações de modo a favorecer o entendimento dos conceitos adequadamente e que contribua para a formação de cidadãos 
críticos, éticos e responsáveis. A implementação de políticas educacionais voltadas para o livro didático, com destaque para o Programa Nacional do Livro Didático (PNLD), agora chamado de Programa Nacional do Livro Didático e do Material Didático (PNLD), tem contribuído para a compra e fornecimento de livros com melhor qualidade, com base em avaliação criteriosa das obras a serem distribuídas nas escolas públicas.

Os livros didáticos de Química passaram a fazer parte do Programa a partir de 2009. Entre os aspectos considerados na avaliação dos materiais, estão a abordagem teóricometodológica e a proposta didático-pedagógica neles presentes (ALVES; MAGALHÃES JÚNIOR, 2020). Com isso, ao longo dos anos, as editoras tiveram que modificar os livros didáticos para atender ao exposto nos editais do PNLD caso tivessem interesse em fornecer esses materiais para as escolas públicas. Porém, apesar de as pesquisas na Didática das Ciências apontarem para a necessidade de materiais que superem a perspectiva tradicional de apresentação dos conteúdos, há resistência dos professores em adotar materiais de caráter mais inovador. As editoras também interferem e modificam os materiais para atender às exigências de mercado, o que contribui para a manutenção de obras que mantêm o viés tradicional (ROSA, 2017).

A elevada utilização das analogias, principalmente nos livros de Química destinados ao ensino médio, acabou impulsionando, nos últimos anos, estudos com o intuito de avaliar a qualidade com que eram abordadas. Conteúdos que apresentam certo grau de abstração, como por exemplo estrutura atômica e ligações químicas, geralmente, são os que mais apresentam analogias (RIBEIRO, 2016).

Recorrendo à literatura sobre o uso delas, é possível encontrar trabalhos que relatam as potencialidades e os problemas identificados. Monteiro e Justi (2000), Oliveira (2015) e Santana et al. (2017) explanaram as dificuldades relacionadas ao ensino de conceitos químicos e debateram o uso de analogias como estratégia no processo ensino-aprendizagem.

Monteiro e Justi (2000), em seus estudos sobre analogias nos livros didáticos de Química, encontraram um total de 126 analogias em livros didáticos do ensino médio e observaram, para a maioria dos casos, que elas pouco contribuíram para a compreensão do conceito-alvo. Oliveira (2015) classificou diversas analogias encontradas nos livros de Química aprovados pelo PNLD e chegou à conclusão de que a maioria era exposta de maneira espontânea e poderia eventualmente levar a entendimentos equivocados. Para Clement (2006), essas exposições espontâneas e superficiais podem ser explicadas pelo simples fato de que essas 
analogias são compreendidas como óbvias pelos elaboradores de materiais didáticos, porém, elas não são entendidas da mesma maneira pelos estudantes.

Sabe-se que a ausência de discussões mais eficazes sobre as relações analógicas, bem como a falta de reconhecimento das limitações, são alguns dos empecilhos pelos quais as analogias acabam falhando para mediar a relação entre os estudantes e professores de modo que contribua para o aprendizado dos conceitos. Além do mais, conforme apontado na literatura, entende-se que a analogia pouco contribui para a aprendizagem se não houver um conhecimento bem fundamentado sobre o uso dessa estratégia.

Assim, nota-se que são relativamente escassos os trabalhos que discutem os reais problemas conceituais que essa estratégia pode abarcar quando exposta de maneira espontânea e superficial nos livros didáticos. Somado a isso, é interessante ressaltar a grande influência do livro didático no ensino médio, principalmente por ser, em muitas situações, o principal recurso didático à disposição do professor em sala de aula.

Nesse sentido, o presente artigo descreve a categorização das analogias encontradas nos conteúdos de estrutura atômica dos livros didáticos aprovados pelo PNLD 2018 e explora eventuais erros conceituais a que essa estratégia poderia levar quando utilizada de maneira inadequada.

\section{Metodologia}

Para a realização da pesquisa, foram analisados os seis livros didáticos de Química referentes ao primeiro volume das obras aprovados pelo PNLD 2018, conforme mostrado no Quadro 1. Baseando-se nos trabalhos de Monteiro e Justi (2000), o conteúdo selecionado para a análise da presença de analogias foi o de modelos atômicos, justamente por esse ter um grau de abstração elevado e por conter, historicamente, um alto índice de analogias.

Quadro 1 - Relação dos livros aprovados pelo PNLD 2018 e que foram analisados

\begin{tabular}{|c|c|c|c|c|c|}
\hline Obra & Autor(es) & Título & Editora & Edição & Ano \\
\hline $\mathbf{0 1}$ & Martha Reis & Química & Ática & $2^{\text {a }}$ & 2016 \\
\hline $\mathbf{0 2}$ & Eduardo Fleury Mortimer e Andréa Horta \\
Machado & Química & Scipione & $3^{\text {a }}$ & 2016 \\
\hline $\mathbf{0 3}$ & Wildson L. P. dos Santos e Gerson Mól & Química Cidadã & AJS & $3^{\text {a }}$ & 2016 \\
\hline $\mathbf{0 4}$ & $\begin{array}{c}\text { Julio Cezar F. Lisboa, Aline T. Bruni, Ana Luiza } \\
\text { P. Nery, Rodrigo M. Liegel e Vera Lúcia M. Aoki }\end{array}$ & $\begin{array}{c}\text { Ser } \\
\text { Protagonista }\end{array}$ & SM & $3^{\text {a }}$ & 2016 \\
\hline $\mathbf{0 5}$ & Vera L. D. de Novais e Murilo T. Antunes & Vivá & Positivo & $1^{\text {a }}$ & 2016 \\
\hline $\mathbf{0 6}$ & $\begin{array}{c}\text { Carlos A. M. Ciscato, } \\
\text { Luis F. Pereira, Emiliano C. e Patrícia B. Proti }\end{array}$ & Química & Moderna & $1^{\text {a }}$ & 2016 \\
\hline
\end{tabular}

Fonte: Elaborado pelos autores 
De início, foram identificadas as analogias considerando-se a definição proposta por Gentner (1989). Uma vez identificadas, elas foram classificadas com base nos critérios delineados por Thiele e Treagust (1994) e adaptados por Monteiro e Justi (2000) que são:

- Relações Analógicas: Tipo de atributos (estruturais ou funcionais) entre o domínio análogo e o conceito-alvo. A relação é denominada estrutural quando o análogo e o alvo "podem apresentar semelhanças físicas, ou então ser construídos similarmente" (CURTIS; REIGELUTH, 1984, p. 103). Por outro lado, a relação funcional é aquela em que: "a função ou comportamento do análogo é atribuída ao alvo" (THIELE; TREAGUST, 1994, p. 67).

- Formato: Se o formato de apresentação da analogia é verbal ou ilustrativo-verbal. Nesse critério, a analogia foi classificada como verbal quando aparecia descrita apenas no texto ou ilustrativa-verbal quando a ilustração e o texto em si representavam o análogo (THIELE; TREAGUST, 1984).

- Nível de Abstração: Se o domínio análogo e conceito-alvo estão em um nível cognitivo abstrato ou concreto. Nessa categoria de análise, a condição do análogo e do alvo foi classificada como concreta/abstrata, abstrata/abstrata ou concreta/concreta. Na primeira condição, a natureza do análogo era concreta e a do alvo era abstrata. Por outro lado, quando a natureza de ambos (domínio análogo e conceito-alvo) era abstrata ou concreta, a condição da analogia foi classificada como abstrata/abstrata e concreta/concreta, respectivamente (CURTIS; REIGELUTH, 1984).

- Enriquecimento: Analisa-se em que extensão o mapeamento entre a analogia e o alvo é feita pelo autor. Nesse critério, o nível de enriquecimento da analogia é dito simples quando o domínio da analogia é conectado ao domínio-alvo usando expressões características do tipo "é como", "pode ser comparado a", "é semelhante a". No entanto, a analogia poderá ser enriquecida quando os atributos compartilhados entre o domínio análogo e o conceitoalvo estão explicitados (CURTIS; REIGELUTH, 1984).

- Limitação: a) não reconhecem limitações para o uso das analogias; b) reconhecem a existência das limitações, mas não as discutem, ou pelo menos não discutiram algumas delas (MONTEIRO; JUSTI, 2000).

Por fim, após a classificação das analogias encontradas nos livros didáticos que foram analisados segundo os critérios descritos e comentados anteriormente, a última etapa visa avaliar as possíveis contribuições ou também erros conceituais que as analogias comumente encontradas podem causar em relação ao entendimento do conceito-alvo. 


\section{RESUltAdOS E DISCUSSÃO}

Analisando os livros didáticos aprovados pelo PNLD 2018, foram identificadas e categorizadas 16 analogias. A Figura 3 apresenta o quantitativo de analogias relativas ao conteúdo de estrutura atômica e indica que a obra 04, Ser Protagonista, não faz uso desse recurso para a discussão dos conceitos.

Entre os livros analisados, os que apresentaram maior número de analogias foram: Vivá, Química de autoria da Martha Reis e Química Cidadã, todos com quatro analogias cada. No livro Química, de Mortimer e Machado, foi identificado um total de três analogias e no de autoria de Ciscato e colaboradores, apenas uma.

Figura 3 - Quantidade de analogias relativas ao conteúdo estrutura atômica nas obras aprovadas no PNLD 2018

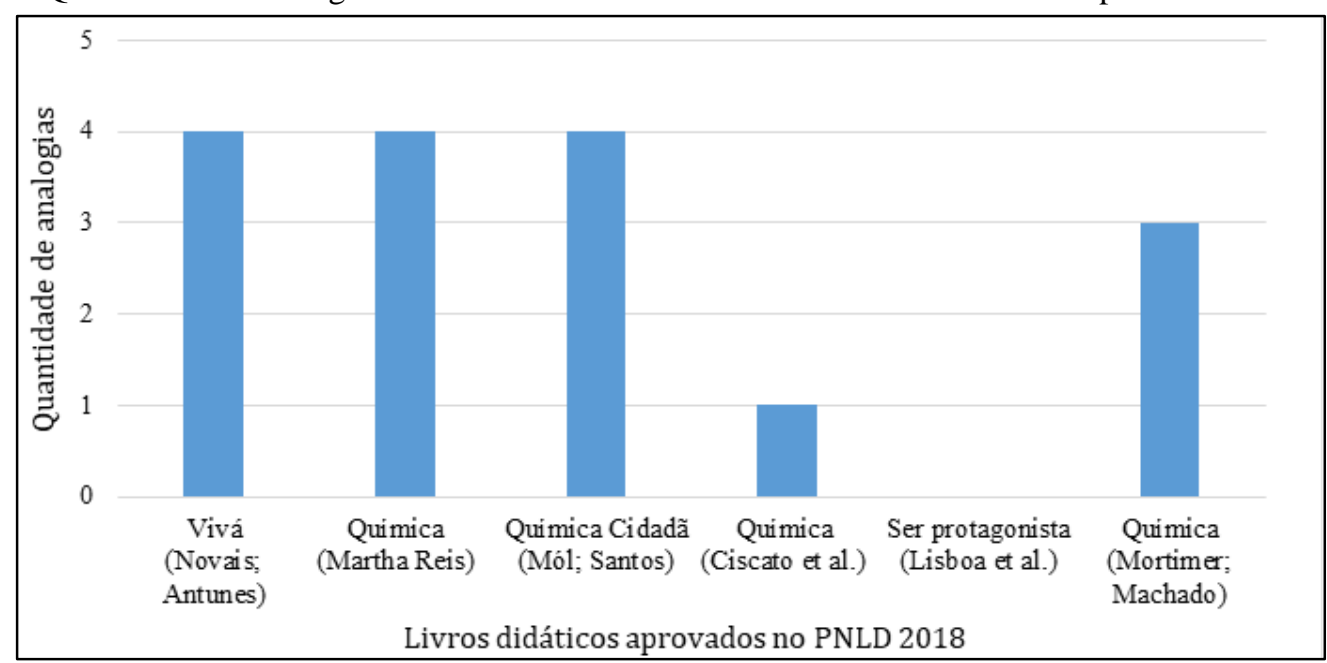

Fonte: Elaborado pelos autores

Em relação aos modelos atômicos representados pelas analogias, foi observado que seis delas representavam o modelo atômico proposto por Thomson e 10 o modelo conhecido como Rutherford-Bohr. Não foi identificado o uso de analogias referentes ao modelo elaborado por Dalton.

Uma analogia de uso bastante tradicional para o modelo atômico proposto por John Dalton (1766-1844) associava o átomo a uma bola de bilhar. Tal comparação não foi encontrada em nenhum dos livros do presente estudo. Uma justificativa para isso seria os possíveis problemas que ela pode gerar quando utilizada de maneira equivocada, já que foram relatadas associações errôneas, incoerentes e superficiais de alunos com base na utilização dessa analogia (MUNARIN; MUNARIN, 2008; FERNANDES, 2017).

Na pesquisa desenvolvida por Munarin e Munarin (2008), por exemplo, identificou-se que a comparação entre o átomo, conforme proposto por Dalton, e uma bola de bilhar, fez com que estudantes acreditassem que os átomos tinham uma espécie de mancha, em razão das bolas 
de sinuca normalmente apresentarem uma parte de coloração diferente com um número pintado. No trabalho desenvolvido por Fernandes (2017), identificou-se a presença dessa analogia na edição anterior do livro Química Cidadã (PNLD-2015) o que, conforme análise na presente pesquisa, não ocorre nos livros didáticos aprovados no PNLD-2018. A remoção dessa tradicional analogia pode estar associada à existência de trabalhos que demonstram as possíveis consequências da má utilização e porque o modelo atômico de Dalton é estruturalmente mais simples quando comparado aos demais modelos atômicos, não havendo tanta necessidade da utilização de uma analogia para a sua compreensão.

\subsection{ANALOgIAS REFERENTES AO MODELO ATÔMICO DE THOMSON}

Em relação ao modelo atômico de Thomson, foram encontradas seis analogias, como explicitado no Quadro 2. Para esse modelo atômico, metade das obras analisadas apresentam o uso de analogias.

Quadro 2 - Quantidade de analogias referente ao modelo atômico de Thomson por livro didático

\begin{tabular}{|c|c|c|c|c|c|c|}
\hline Obras analisadas & Obra 01 & Obra 02 & Obra 03 & Obra 04 & Obra 05 & Obra 06 \\
\hline $\begin{array}{l}\text { Quantidade de } \\
\text { Analogia(s) }\end{array}$ & 2 & 1 & 3 & - & - & - \\
\hline $\begin{array}{c}\text { Analogia(s) } \\
\text { encontrada(s) }\end{array}$ & $\begin{array}{l}\text { Pudim de } \\
\text { passas (2) }\end{array}$ & Panetone & $\begin{array}{c}\text { - Pudim de } \\
\text { ameixas (2) } \\
\text { - Bolas de gude } \\
\text { e balas de } \\
\text { canhão }\end{array}$ & - & - & - \\
\hline
\end{tabular}

Fonte: Elaborado pelos autores

Uma analogia bastante recorrente para esse modelo atômico e que foi encontrada nas obras 01 (Química: Martha Reis) e 03 (Química Cidadã) é a do "pudim de passas/ameixas", utilizada, historicamente, com o intuito de favorecer a compreensão do modelo atômico proposto por J. J. Thomson (1856-1940). Na obra 03 também foi encontrada analogia sobre o experimento das partículas alfa (bolas de gude e balas de canhão). Já na obra 02 (Química: Mortimer e Machado) foi identificada a utilização do panetone como domínio análogo. Dessas analogias, as que foram representadas utilizando uma imagem são apresentadas na Figura 4. 
Figura 4 - Analogias relativas ao modelo atômico de Thomson identificadas nos livros didáticos aprovados no PNLD 2018. A) Analogia na obra 01. B) Analogia na obra 02. C) Analogia na obra 03

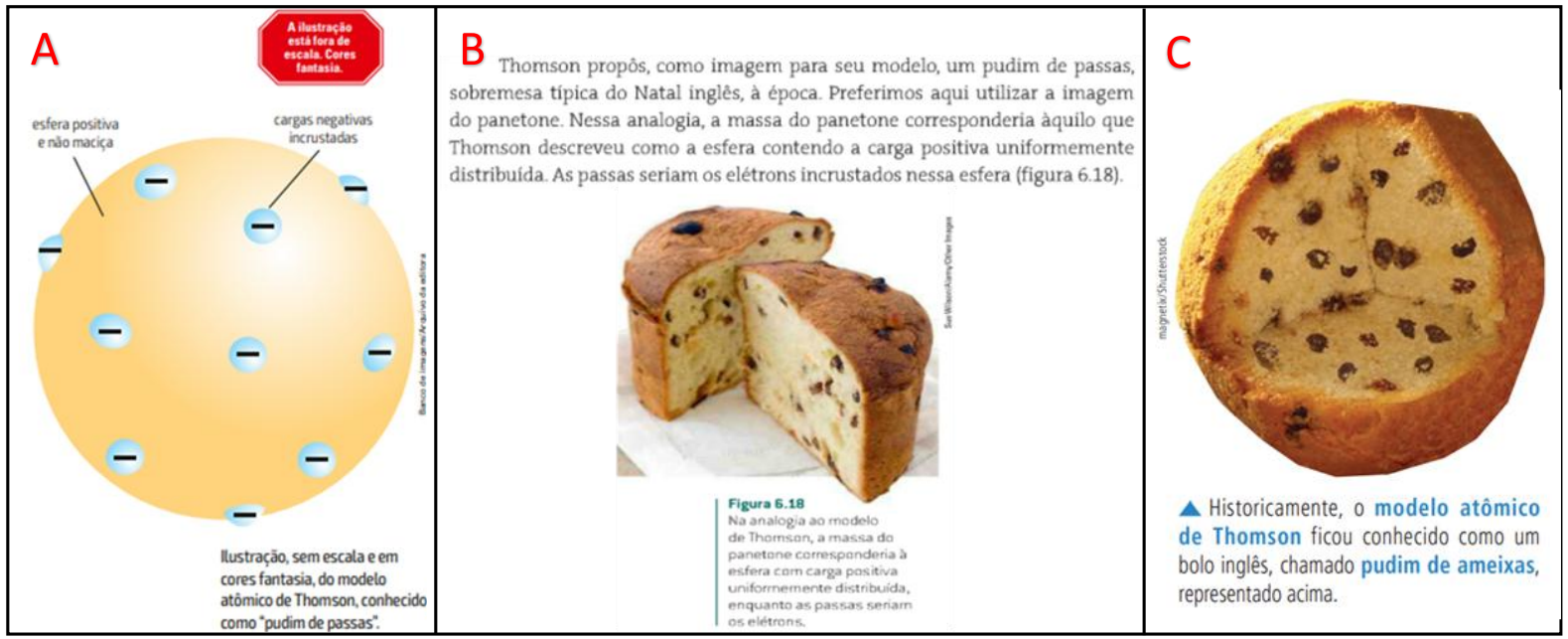

Fonte: A) Química: Fonseca, 2016, p. 147; B) Química: Mortimer e Machado, 2016, p. 146; C) Química Cidadã, 2017, p. 158.

Na Figura 4A, da obra 01, observa-se, abaixo da imagem, uma legenda que se refere ao modelo de Thomson como "pudim de passas". Essa ideia aparece uma segunda vez no corpo do texto apresentado no trecho a seguir:

Interpretando os resultados de uma grande série de experimentos, a equipe de Rutherford chegou à conclusão de que o átomo não se parecia com uma esfera positiva com elétrons incrustados (como um "pudim de passas”) (FONSECA, 2016, p. 150).

$\mathrm{Na}$ Figura 4B, encontrada na obra 02, a analogia relaciona as passas dispersas pelo panetone como sendo equivalentes aos elétrons dispersos por todo átomo e a massa distribuída uniformemente seria como a massa eletricamente positiva.

Já na Figura 4C, relativa à obra 03, apesar de não apresentar as relações analógicas na forma escrita, a imagem induz uma comparação do modelo atômico de Thomson com um panetone. No corpo do texto, os autores destacam o uso corriqueiro desse modelo:

Esse modelo teórico acabou sendo popularizado em livros didáticos com a denominação de "pudim de ameixas", em referência a um bolo inglês que em nada se assemelha ao nosso pudim de ameixas (SANTOS; MÓL, 2016, p. 160).

A primeira categoria de análise se refere às relações analógicas identificadas. Interpretando conjuntamente essas comparações, percebe-se que as relações entre os domínios análogos e o conceito-alvo são todas do tipo estruturais. Essas analogias relacionadas ao "pudim de passas" e "panetone" são classicamente utilizadas nas aulas de química. Na maioria dos casos, o uso dessa analogia é classificado como uma analogia estrutural, compartilhando, principalmente, um aspecto estrutural que as passas dispersas no pudim/panetone seriam como os elétrons dispersos pela esfera não maciça do átomo. 
Além dessas, na obra 03, foi encontrada uma analogia que envolvia o experimento das partículas alfa realizado por Rutherford. No livro Química Cidadã, para explicar os resultados desse experimento, compara-se a dificuldade que os elétrons teriam em desviar a trajetória das partículas alfa com a dificuldade de bolas de gude em desviar balas de canhão, conforme trecho a seguir:

De acordo com o modelo atômico de Thomson, as deflexões seriam improváveis: sendo muito mais leves que as partículas alfa, os elétrons teriam tanta dificuldade para desviar suas trajetórias quanto bolas de gude para desviar balas de canhão (SANTOS; MÓL, 2016, p. 163, grifo nosso).

Em razão de o domínio análogo compartilhar uma semelhança comportamental (velocidade) e estrutural (grande diferença de massas) com o conceito-alvo, essa analogia é descrita como sendo do tipo funcional-estrutural.

Estudos recentes envolvendo esse tipo de estratégia demonstram que as analogias que apresentam uma relação funcional-estrutural são potencialmente mais eficazes, afinal, existe um compartilhamento maior das semelhanças entre o domínio análogo e o conceito-alvo, superando, portanto, as limitações existentes. Entretanto, apesar dessa característica favorável, não se torna menos importante o uso das analogias que possuem apenas características estruturais ou funcionais isoladas (MONTEIRO; JUSTI, 2000).

A segunda categoria de análise se refere ao formato da apresentação. Como foi demonstrado nos resultados obtidos, das seis analogias envolvendo o modelo atômico de Thomson, a identificada na obra 02 (Figura 4B, Mortimer e Machado, 2016, p. 146) foi caracterizada como sendo ilustrativa-verbal (analogia do panetone); a da obra 03 (Figura 4C, Química Cidadã, 2017, p. 158) é do tipo ilustrativa (analogia do pudim de passas). As outras três analogias foram classificadas como sendo do tipo verbais.

Representações ilustrativas do domínio análogo são interessantes pois possibilitam maior formulação mental de conceitos abstratos de difícil interpretação. Entretanto, dependendo da analogia utilizada, apenas a visualização da ilustração não garante que a formulação ou o entendimento do conceito seja obtido. Observa-se na Figura 4C que, apesar da ilustração do pudim de passas, a analogia poderia ser mais bem compreendida caso o domínio análogo fosse descrito verbalmente também, propiciando um entendimento maior acerca das relações analógicas entre os domínios.

Já sobre a categoria concernente ao nível de abstração, duas analogias encontradas foram classificadas como sendo do tipo concreta/abstrata (Figura 4B e citação direta da página anterior de Mól e Santos, 2016, p. 163, que se refere a bolas de gude e balas de canhão). As 
outras quatro analogias comparam o modelo a um pudim de passas (Química - Martha Reis) e a um pudim de ameixas (Química Cidadã), sendo classificadas como abstrata/abstrata. Estudos evidenciam que o pudim de passas enquanto domínio análogo não é familiar para muitos estudantes, o que dificulta a imaginação e associação das características semelhantes dessa analogia com o modelo atômico de Thomson. No caso do pudim de ameixas, destacado na obra 03, Química Cidadã, observa-se que ele não se assemelha com o pudim brasileiro tradicional, porém, não é possível afirmar que os estudantes conheçam as características do alimento de modo a considerá-lo concreto.

Desse modo, é importante destacar que na analogia que utiliza o panetone, os autores fazem questão de explicitar a preferência pela utilização desse domínio análogo. Essa preferência pode ser justificada pelo fato de os estudantes terem maior familiaridade com esse domínio do que com o pudim de passas que, na culinária brasileira, é um tanto desconhecido.

Em relação à categoria nível de enriquecimento, das seis analogias encontradas, cinco delas foram classificadas como simples e apenas a analogia do panetone, ilustrada na Fig. 4B (MORTIMER; MACHADO, 2016, p. 146), foi classificada como sendo enriquecida. Nela, os autores fazem questão de destacar que, assim como as passas no panetone, os elétrons também estariam distribuídos uniformemente no átomo. Essas conexões existentes entre o domínio análogo e o conceito-alvo, claramente abordadas pelos autores, são importantes para que os professores e os estudantes consigam compreender o domínio análogo e, consequentemente, o conceito-alvo, tornando a utilização da analogia enriquecida mais apropriada.

As demais analogias foram classificadas como simples, pois os autores omitem as características similares com os seus respectivos conceitos-alvo. Na maioria dos casos em que as analogias são classificadas como sendo do tipo simples, necessita-se que os alunos se responsabilizem por identificar não apenas as características em comum, mas também os atributos que não são compartilhados, ou seja, as limitações. Isso, a depender da analogia utilizada, pode acabar dificultando a compreensão do conceito-alvo, ainda mais quando as características similares não são claramente perceptíveis.

A última categoria de análise se refere à limitação das analogias. E, para as analogias que envolviam o modelo atômico de Thomson, não foi observado o reconhecimento das limitações das analogias identificadas. Nesse sentido, quando as limitações não são claramente discutidas ou abordadas, os alunos podem acabar interpretando de maneira equivocada as características em comum com o conceito-alvo. Adicionalmente, existe ainda um cuidado 
eminente acerca da extensão da analogia e da possibilidade de os estudantes a utilizarem em outros conceitos que não se assemelham com o conceito em questão.

Particularmente, as analogias envolvendo o "pudim de passas/ameixas" e o "panetone" encontradas aqui apresentaram algumas limitações intrínsecas. Isso porque elas podem levar os estudantes a pensarem que, assim como as passas dispersas no domínio análogo, os elétrons estariam também distribuídos pontualmente pelo átomo, o que não coaduna com o descrito no modelo em questão. Thomson (1904) propôs para o seu modelo que os elétrons (corpúsculos) estariam em constante movimento, com a carga positiva ocupando o volume total do átomo.

Em complemento, é importante salientar dois pontos cruciais que tornam essa analogia ainda mais limitada:

- A utilização de um modelo atípico da culinária brasileira, pudim de ameixas, produz um domínio análogo menos familiar para os estudantes, o que torna a construção das relações analógicas mais dificultadas.

- Não há relatos que, de fato, Thomson (1904) atribuiu o termo "pudim de passas" ao seu modelo atômico, como afirmado na descrição da analogia na Figura 4B.

Portanto, considerando esses pontos, nota-se que esses modelos estáticos estão muito distantes daquilo que Thomson propôs para seu modelo, levando a classificá-los como sendo bastante limitados (LOPES; MARTINS, 2009).

\subsection{ANALOGIAS REFERENTES AO MODELO ATÔMICO DE RUTHERFORD-BOHR}

Em relação ao modelo atômico de Rutherford-Bohr, foi encontrado um total de 10 analogias, como mostrado no Quadro 3 que relaciona a quantidade delas para cada obra analisada.

Quadro 3 - Quantidade de analogias envolvendo o modelo atômico de Rutherford-Bohr por livro didático

\begin{tabular}{|c|c|c|c|c|c|c|}
\hline $\begin{array}{c}\text { Obras } \\
\text { analisadas }\end{array}$ & Obra 01 & Obra 02 & Obra 03 & Obra 04 & Obra 05 & Obra 06 \\
\hline $\begin{array}{l}\text { Quantidade } \\
\text { de Analogias }\end{array}$ & 2 & 2 & 1 & - & 4 & 1 \\
\hline $\begin{array}{l}\text { Analogia(s) } \\
\text { encontrada(s) }\end{array}$ & $\begin{array}{c}\text { - Sistema } \\
\text { planetário } \\
- \\
\text { Experimento } \\
\text { partículas alfa }\end{array}$ & $\begin{array}{l}\text { - Sistema } \\
\text { planetário }\end{array}$ & $\begin{array}{c}\text { - Sistema } \\
\text { planetário }\end{array}$ & - & $\begin{array}{c}\text { - Sistema } \\
\text { planetário } \\
- \\
\text { Experimento } \\
\text { partículas alfa } \\
\text { (2) } \\
\text { - Tamanho do } \\
\text { átomo }\end{array}$ & $\begin{array}{l}\text { - Planeta } \\
\text { saturno }\end{array}$ \\
\hline
\end{tabular}

Fonte: elaborado pelos autores 
Os resultados indicam que praticamente todos os livros didáticos analisados fazem uso dessa estratégia para o modelo em questão, à exceção da obra 04, Ser Protagonista. A analogia tradicionalmente utilizada que compara esse modelo atômico ao sistema planetário foi a mais encontrada e, além dessa, apareceram outras envolvendo o experimento realizado por Rutherford utilizando as partículas alfa e também a diferença de tamanho entre o núcleo e o átomo como um todo.

Em relação à analogia que compara o modelo proposto por Rutherford com o sistema planetário foram identificadas as imagens apresentadas na Figura 5. Além delas, analogias referentes ao sistema planetário também apareceram descritas na forma de textos nas obras analisadas.

Figura 5 - Analogias comparando o sistema planetário ao modelo atômico de Rutherford identificadas nos livros didáticos aprovados no PNLD 2018. A) Analogia na obra 1; B) Analogia na obra 3

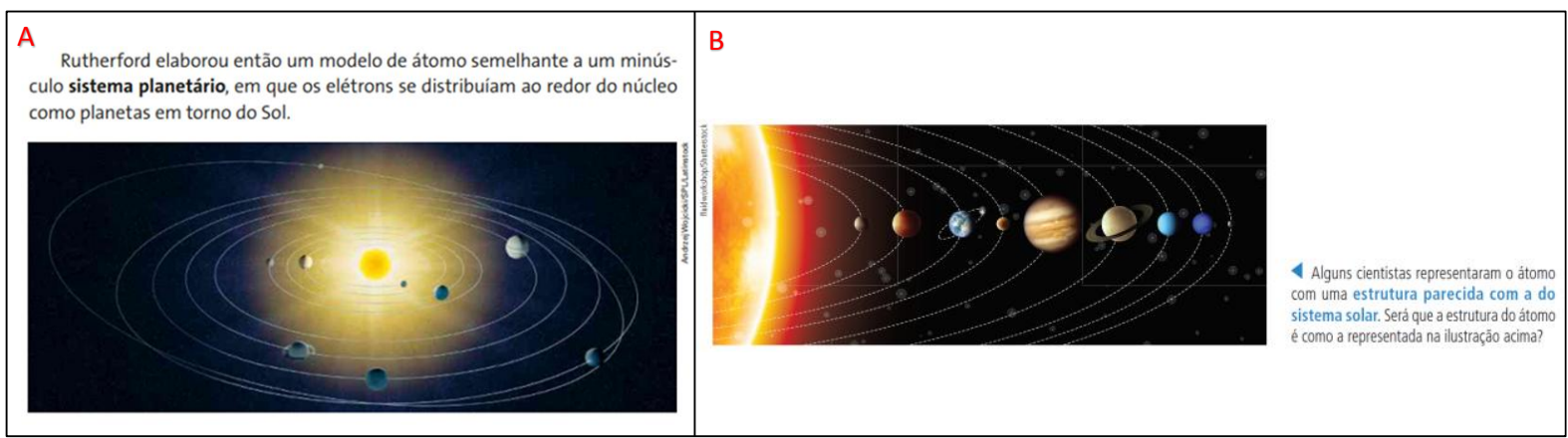

Fonte: A) Química - Martha Reis - Fonseca, 2016, p. 150); B) Química Cidadã, 2017, p. 161

As analogias descritas no corpo do texto foram apresentadas no Quadro 4. Para facilitar a discussão, foi criado um código correspondendo ao Modelo de Rutherford (MD), número da obra e número da analogia.

Quadro 4 - Analogias envolvendo o modelo atômico de Rutherford-Bohr descritas no corpo do texto por livro didático

\begin{tabular}{|c|c|l|c|c|}
\hline Código & Obra & \multicolumn{1}{c|}{ Transcrição da analogia } & $\begin{array}{c}\text { Analogia } \\
\text { encontrada }\end{array}$ \\
\hline MD01-1 & $\begin{array}{c}\text { Química } \\
\text { Martha } \\
\text { Reis }\end{array}$ & $\begin{array}{l}\text { Esperava-se que a grande energia cinética das partículas alfa as faria } \\
\text { atravessar uma finíssima folha metálica de ouro (de aproximadamente 10-4 } \\
\text { mm de espessura), tal como uma bala de espingarda atravessa uma folha } \\
\text { de papel sem ser rebatida por ela (FONSECA, 2016, p. 148, grifo nosso). }\end{array}$ & $\begin{array}{c}\text { Experiment } \\
\text { o partículas } \\
\text { alfa }\end{array}$ \\
\hline MD02-1 & $\begin{array}{c}\text { Química } \\
\text { Mortimer } \\
\text { Machado }\end{array}$ & $\begin{array}{l}\text { No modelo proposto por Rutherford, os elétrons eram representados } \\
\text { descrevendo órbitas circulares em torno do núcleo, de forma análoga aos } \\
\text { planetas em órbita do sol (Química - Mortimer, Machado, 2016, p. 149). }\end{array}$ & $\begin{array}{c}\text { Tamanho } \\
\text { do átomo }\end{array}$ \\
\hline MD05-1 & $\begin{array}{c}\text { Vivá } \\
\text { Antunes }\end{array}$ & $\begin{array}{l}\text { Uma explicação natural para alguns cientistas era propor que o movimento } \\
\text { dos elétrons deveria ser análogo ao movimento dos planetas em órbita ao } \\
\text { redor do sol. Ora, mas com base nas leis do Eletromagnetismo, já } \\
\text { conhecidas na época, elétrons em movimento irradiam energia } \\
\text { continuamente. Com isso, o raio da órbita diminuiria, o que também } \\
\text { levaria os elétrons a colidirem com o núcleo. Cálculos matemáticos }\end{array}$ & $\begin{array}{c}\text { Tamanho } \\
\text { do átomo }\end{array}$ & \\
\hline
\end{tabular}




\begin{tabular}{|c|c|c|c|}
\hline & & $\begin{array}{l}\text { indicam que isso ocorreria quase instantaneamente (Vivá - Novais; } \\
\text { Antunes, 2016, p. 91). }\end{array}$ & \\
\hline MD05-2 & $\begin{array}{l}\text { Vivá } \\
\text { Novaes; } \\
\text { Antunes }\end{array}$ & $\begin{array}{l}\text { O que mais surpreendeu nesse experimento foi o fato de que essas poucas } \\
\text { radiações que não atravessaram a lâmina metálica voltavam em direção a } \\
\text { fonte de radiação. Rutherford descreveu o seu espanto afirmando que isso } \\
\text { tinha sido a coisa mais incrível que havia acontecido, que era quase tão } \\
\text { incrível quanto se atirássemos uma granada de } 15 \text { polegadas contra uma } \\
\text { folha de papel e a granada voltasse e nos atingisse (Vivá, 2017, p. 89). }\end{array}$ & $\begin{array}{l}\text { Experiment } \\
\text { o partículas } \\
\text { alfa }\end{array}$ \\
\hline MD05-3 & $\begin{array}{l}\text { Vivá } \\
\text { Novaes; } \\
\text { Antunes }\end{array}$ & $\begin{array}{l}\text { Vale destacar que uma partícula } \alpha \text { tem massa quase } 8000 \text { vezes maior que } \\
\text { a do elétron. Fazendo uma analogia, poderíamos imaginar algo como um } \\
\text { caminhão (partícula } \alpha \text { ) em alta velocidade atropelando uma lata de ferro (o } \\
\text { elétron) (Vivá, 2017, p. 90). }\end{array}$ & $\begin{array}{l}\text { Experiment } \\
\text { o partículas } \\
\text { alfa }\end{array}$ \\
\hline MD05-4 & $\begin{array}{l}\text { Vivá } \\
\text { Novaes; } \\
\text { Antunes }\end{array}$ & $\begin{array}{l}\text { Para reforçar o que vimos, imagine um depósito de petróleo, cuja massa } \\
\text { seja da ordem de } 2.108 \mathrm{~kg} \text {, isto é, } 200000000 \mathrm{~kg} \text {, ou } 200 \text { mil toneladas; } \\
\text { se, magicamente, pudéssemos remover todas as eletrosferas dos átomos } \\
\text { nele existentes, ele passaria a ocupar um volume menor do que o de uma } \\
\text { gota. Ou seja, a matéria é constituída de diminutos núcleos com carga } \\
\text { positiva, extremamente densos, cercados por uma região praticamente } \\
\text { "vazia", na qual estão os elétrons, de carga negativa (Vivá, 2017, p. 90). }\end{array}$ & $\begin{array}{l}\text { Tamanho } \\
\text { do átomo }\end{array}$ \\
\hline MD06-1 & $\begin{array}{l}\text { Química } \\
\text { Ciscato } \\
\text { et al. }\end{array}$ & $\begin{array}{l}\text { Nesse meio tempo, Rutherford entrou em contato com as ideias do físico } \\
\text { japonês Hantaro Nagaoka [...] Nagaoka propôs, em 1904, um modelo } \\
\text { diferente do proposto por Thomson. Segundo ele, os elétrons estariam } \\
\text { situados fora da esfera positivamente carregada, descrevendo órbitas } \\
\text { circulares ao redor dela. Ou seja, o volume total do átomo não seria } \\
\text { ocupado pela esfera positiva nesse modelo, chamado de Saturniano em } \\
\text { alusão ao planeta Saturno e seu sistema de anéis (CISCATO et al., 2017, } \\
\text { p. 89). }\end{array}$ & $\begin{array}{l}\text { Planeta } \\
\text { saturno }\end{array}$ \\
\hline
\end{tabular}

Fonte: elaborado pelos autores

Conforme descrito no Quadro 4, além das imagens que comparam o modelo de Rutherford com o sistema planetário, ilustradas na Figura 5, foi identificada no corpo do texto a analogia MD05-1 disponível na obra Vivá. Há ainda uma analogia, MD06-1, que relaciona o átomo ao planeta Saturno.

A segunda analogia mais frequente se refere ao experimento realizado por Rutherford utilizando partículas alfa, que aparece uma vez no livro Química - Martha Reis, transcrita na Quadro 4, analogia MD01-1, e duas vezes no livro Vivá, analogias MD05-2 e MD05-3.

Por fim, foram identificadas analogias relativas ao modelo de Rutherford que se referem ao tamanho do núcleo do átomo em comparação ao tamanho do átomo inteiro. Uma delas está presente na obra 02, de autoria de Mortimer e Machado (2016), e é apresentada na Fig. 6. Além dessa, no livro Vivá (obra 05), o volume ocupado pela eletrosfera do átomo foi relacionado a um depósito contendo 200 mil toneladas de petróleo, conforme descrito na analogia MD05-4, apresentada no Quadro 4. 
Figura 6 - Analogia encontrada na obra 02 envolvendo o estádio Maracanã, relacionando a diferença de tamanho entre o núcleo atômico e o átomo com uma pulga no centro do estádio

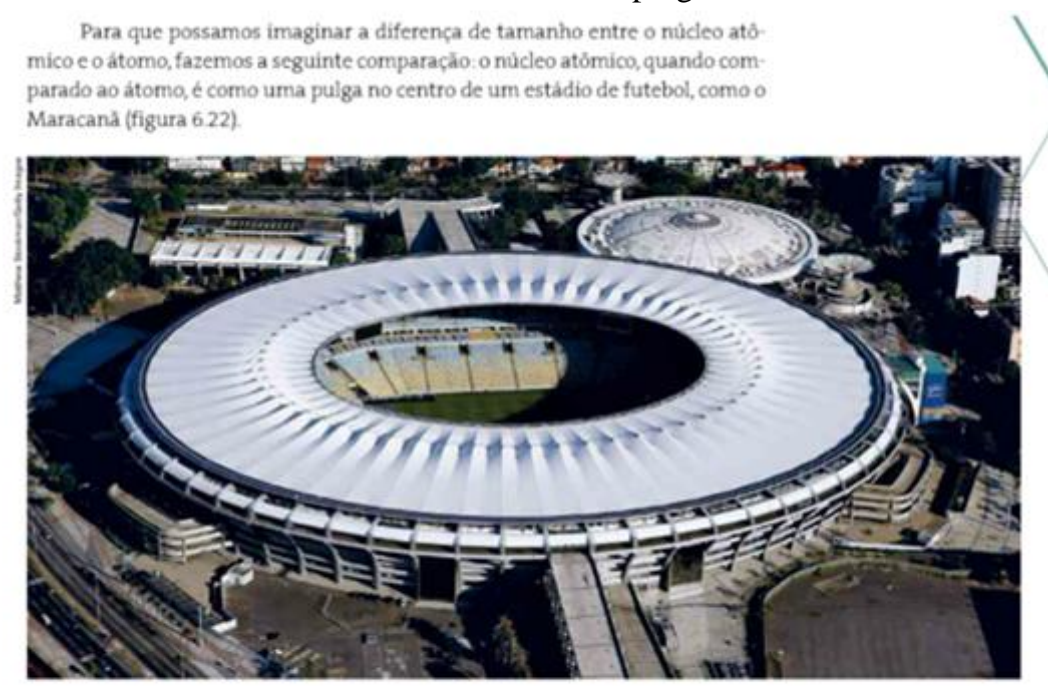

Essa comparação deve ser levada em conta para que possamos interpretar corretamente as representações normalmente feitas do átomo. Isso significa compreender que, dada a impossibilidade prática de representar os constituintes do átomo nas escalas corretas, o núcleo é sempre superdimensionado.

Fonte: Mortimer e Machado (2016), p. 149

As analogias identificadas foram classificadas como sendo a primeira categoria referente às relações analógicas. As analogias ilustradas na Figura 5, presentes nas obras $01 \mathrm{e}$ 03, fazem uma comparação do sistema planetário, em que a disposição espacial dos planetas em torno do sol seria análoga à disposição espacial dos elétrons em torno do núcleo. Logo, da maneira como foram colocadas, classificamos essas analogias como estruturais. Essa mesma classificação é adotada para a analogia do modelo de Rutherford com o planeta Saturno, analogia MD06-1, presente na obra 06, de Ciscato e colaboradores (2017).

Já na citação de Mortimer e Machado (2016), analogia MD02-1, e na obra Vivá de Novais e Antunes (2016), MD05-1, além da comparação com as características estruturais, os autores enfatizam que o movimento dos elétrons seria análogo ao movimento dos planetas no sistema solar, o que se caracteriza como uma relação funcional. Assim, a interpretação conjunta dessas características sugere que as analogias descritas, na forma como estão explicitadas, são classificadas como do tipo funcional-estrutural.

Em relação às analogias que se referem ao experimento realizado por Rutherford utilizando partículas alfa, na obra 01 de Martha Reis (2016), analogia MD01-1, para se ter uma maior noção sobre a velocidade das partículas, os autores do livro recorrem a uma analogia que relaciona a velocidade de uma bala de espingarda atravessando uma folha de papel com a velocidade das partículas alfa atravessando a lâmina de ouro. Essa analogia é caracterizada como sendo do tipo funcional porque relaciona apenas a velocidade do domínio análogo (bala 
de espingarda) com a velocidade do conceito-alvo (partículas alfa). Já as analogias MD05-2 e MD05-3 presentes no livro Vivá (2016), referentes a esse experimento, são consideradas como estruturais-funcionais, pois os autores relacionam a dificuldade das partículas alfa retornarem ao serem lançadas contra a lâmina de ouro, comparando com a dificuldade da granada, que apresenta uma massa elevada (caráter estrutural) a certa velocidade (caráter funcional), em retornar ao ser arremessada contra uma folha de papel. Isso vale para quando os autores do livro comparam a massa de uma lata de ferro (que seria análoga ao elétron) com a de um caminhão (partículas alfas). Adicionalmente, eles enfatizam que o caminhão estaria em alta velocidade, assim como as partículas alfa. Essas características estruturais (massa do caminhão) e funcionais (velocidade do caminhão) fazem com que a analogia seja classificada como sendo do tipo estrutural-funcional.

Por fim, na analogia mostrada na Figura 6, do livro de autoria de Mortimer e Machado (2016), os autores afirmam que a diferença de tamanho entre o núcleo atômico e o átomo era tão grande que seria análoga à diferença de tamanho entre uma pulga no centro do Maracanã com o próprio Maracanã. Por conter em comum uma relação estrutural, essa analogia é classificada como sendo do tipo estrutural. Tal classificação também foi adotada para a analogia MD05-4, identificada na obra Vivá (2016), em que os autores enfatizam que a eletrosfera seria constituída de uma região de volume grande e de baixa densidade, assim como um depósito contendo 200 mil toneladas de petróleo que, por ventura, caso se removessem todas as eletrosferas dos átomos que estão ali: o volume ocupado seria semelhante ou menor que a de uma gota. Além disso, os autores afirmam que o átomo seria constituído de uma região praticamente "vazia", na qual estariam os elétrons. Apesar da dificuldade de interpretação da analogia, o fato de os autores exporem uma relação estrutural entre o depósito de petróleo e a eletrosfera do átomo faz com que ela seja do tipo estrutural.

A segunda categoria de análise se refere ao formato da apresentação. Entre as 10 analogias identificadas, apenas três foram classificadas como sendo do tipo ilustrativo-verbal, apresentadas nas Fig. 5 e 6 . As demais analogias são do tipo verbal em que a descrição das semelhanças entre o domínio análogo e o conceito-alvo é abordada ao longo do texto.

Na Figura 5B, que se refere à analogia na obra 03 (Química Cidadã, 2016, p. 161), apesar de conter o sol e os planetas, o sistema solar como um todo é apresentado apenas de maneira parcial. Essa forma de ilustrar não demonstra a visão panorâmica do domínio análogo, o que poderia causar dificuldades na interpretação. 
Apesar de não ser uma regra, existe uma certa tendência quanto ao formato da analogia. Analogias de caráter estrutural, geralmente, apresentam ao menos o domínio análogo na forma ilustrativa. Já as analogias funcionais apresentam o domínio análogo na sua forma verbal. Apesar de intuitivas, essas observações são bastante úteis no sentido de evitar representações inadequadas das analogias e propor, quando possível, combinações do tipo ilustrativas-verbais a fim de tentar tornar o domínio análogo o mais acessível possível.

A terceira categoria se refere ao nível de abstração. Em relação ao modelo atômico Rutherford-Bohr, todas as analogias encontradas foram classificadas como do tipo concreta/abstrata, o que vai ao encontro do princípio básico da analogia, que é a utilização de algo palpável e familiar para facilitar a compreensão de algo abstrato, de difícil compreensão, como é o caso dos modelos atômicos. É importante salientar que, apesar de o sistema solar ser algo distante, esse modelo é largamente abordado em livros didáticos e em outras disciplinas do ensino médio, o que contribui para torná-lo familiar para os estudantes.

Porém, no caso da analogia MD05-4 presente na obra Vivá (2016), que se refere ao depósito de petróleo, apesar de apresentar um domínio análogo familiar, a maneira como esse recurso foi abordado se tornou confusa e de difícil compreensão quanto às semelhanças com o conceito-alvo. Essa observação deixa evidente que apesar da familiaridade com o domínio análogo, algumas analogias podem compartilhar relações analógicas com o conceito-alvo que podem ser incompreensíveis, tornando-se quase uma abstração.

Em relação à categoria nível de enriquecimento, de todas as analogias sobre o modelo atômico de Rutherford, apenas a da Figura 5A presente na obra 01 (Química - Martha Reis Fonseca, 2016) foi classificada como sendo enriquecida. Todas as demais foram do tipo simples em que a menção da analogia se resume a expressões: "semelhante a...", "análogo a...", “como...”. Já no caso da analogia da Figura 5A, são citadas as semelhanças entre o domínio análogo e o conceito-alvo ao mencionar que os elétrons estariam dispostos espacialmente em torno do núcleo assim como os planetas estariam em torno do sol no sistema planetário.

$\mathrm{O}$ adequado seria apresentar as relações analógicas entres os domínios em vez de simplesmente expor a analogia. A presença de discussões que exploram essas relações é bastante enriquecedora e poderia favorecer a compreensão tanto por parte dos professores, quanto, principalmente, por parte dos alunos. No entanto, essas abordagens foram encontradas em praticamente nenhum dos resultados obtidos nesse modelo.

Por fim, em relação às limitações, de todas as analogias encontradas para esse modelo, a única que apresentou um certo reconhecimento da limitação foi a da Figura 5B. Nessa 
analogia os autores questionam se a estrutura atômica é como no sistema planetário. Esse tipo de questionamento é muito importante pois tem o intuito de fazer com que os estudantes reflitam se, de fato, o domínio análogo é semelhante ao conceito-alvo. Nas demais analogias não foi possível observar indícios explícitos de limitação.

Porém, apesar desse ponto benéfico, a analogia em questão apresenta algumas limitações quanto ao seu formato. Os planetas, que fazem alusão aos elétrons, não deveriam estar distribuídos em série porque, em analogia aos elétrons, haveria uma repulsão entre as cargas negativas. Além disso, se levarmos em consideração a dimensão dos planetas, os elétrons, também, deveriam possuir tamanhos distintos, o que não é verdadeiro.

Abordagens incorretas como essas potencializam ainda mais as limitações e fazem com que a analogia atue mais como uma estratégia complicadora do que facilitadora. Uma maneira de melhorar essa analogia seria, primeiramente, alterar a forma como ela está representada, uma vez que a imagem apresenta apenas uma parte do sistema planetário, além de alterar o arranjo espacial dos planetas.

Todas essas analogias categorizadas tiveram, conforme relatado na literatura, poucas contribuições para auxiliar no processo ensino-aprendizagem dos conceitos, sendo observadas exposições espontâneas e superficiais. Essas evidências já foram bastante relatadas e a literatura aponta que a ausência de discussões eficazes sobre as relações analógicas acaba tornando o domínio análogo também de difícil interpretação (MÓL, 1999; MONTEIRO; JUSTI, 2000; OLIVEIRA, 2012).

Nesse sentido, além de escolher uma analogia acessível para os estudantes, os autores devem traçar maneiras adequadas de abordar essa estratégia que incluam, ao menos, formatos, discussões e orientações que objetivem diminuir ao máximo as limitações existentes. Fatores como esses podem favorecer o uso dessa estratégia e promover maior compreensão de muitos conceitos químicos, como, por exemplo, os de estrutura atômica. Superar esses obstáculos é fundamental para a apropriação do conhecimento científico.

\section{CONSIDERAÇões FinaIS}

Na presente pesquisa foi identificado um total de 16 analogias envolvendo o conteúdo de estrutura atômica nos livros didáticos aprovados pelo PNLD 2018, mostrando que, mesmo nos tempos atuais, os elaboradores de materiais didáticos ainda utilizam com frequência as analogias com o objetivo de facilitar a compreensão desse conteúdo que apresenta um alto grau de abstração. Entre essas analogias encontradas, praticamente todas foram apresentadas de 
maneira espontânea, exceto a analogia do panetone. Além disso, fatores como formato, nível de enriquecimento e limitações foram pouco explorados, o que acabou tornando as analogias pouco significativas.

As analogias envolvendo o pudim de passas, panetone e o sistema solar apresentaram mais limitações do que atributos compartilhados. Nota-se que independentemente da maneira como elas foram abordadas, as limitações intrínsecas que essas analogias possuem acabam predominando sobre as relações analógicas, fazendo com que o seu uso não seja o mais recomendado. A utilização de recursos tecnológicos poderia, por exemplo, substituir essas analogias e evitar possíveis erros e dificuldades na aprendizagem.

Faz-se necessária uma avaliação criteriosa dos livros didáticos nas próximas edições do Plano Nacional do Livro e do Material Didático para evitar que estratégias abordadas de maneira equivocada como essas sejam utilizadas. Dessa forma, tanto os professores quanto os estudantes poderão encontrar abordagens que contribuam mais efetivamente para a apropriação de conceitos científicos com base no uso dessa estratégia.

\section{REFERÊNCIAS}

ALVES, Marcos Fernando Soares; MAGALHÃES JÚNIOR, Carlos Alberto de Oliveira. A escolha do livro didático de física e sua utilização em sala de aula. Debates em Educação, v. 12, n. 26, 2020.

AULETE, Francisco Júlio de Caldas; VALENTE, António Lopes dos Santos. Dicionário Contemporâneo da Língua Portuguesa. 6ª edição. Rio de Janeiro. Delta. 1974.

BOZELLI, Fernanda Cátia; NARDI, Roberto. O. Discurso analógico no Ensino Superior. In: NARDI, Roberto; ALMEIDA, Maria José P. M. (Org.). Analogias, leituras e modelos no ensino da ciência: A sala de aula em estudo. São Paulo: Escrituras. 2006.

BRASIL. Ministério da Educação. PNLD 2018: química - guia de livros didáticos - ensino médio/ Ministério da Educação - Secretária de Educação Básica - SEB - Fundo Nacional de Desenvolvimento da Educação. Brasília, DF: Ministério da Educação, Secretária de Educação Básica, 2017. 56 p.

CISCATO, Carlos Alberto Mattoso; PEREIRA, Luis Fernando; PROTI, Patrícia Barrientos. Química: volume 1. São Paulo: Moderna, 2016.

CLEMENT, John. J. Expert novice similarities and instruction using analogies. International Journal of Science Education, v. 20, n. 10, p. 1271-1286, 2006.

CURTIS, Ruth V.; REIGELUTH, Charles M. The use of analogies in written text.

Instructional Science, New York, v. 13, s/n, p. 99-117, 1984. 
DUIT, Reinders. On the role of analogies and metaphors in learning Science. Science Education, v. 75, n. 6, p. 649-672, 1991.

FERNANDES, Mirelly dos Reis. Uma análise semiótica dos modelos atômicos presentes nos livros didáticos adotados pelas escolas públicas da cidade de Goiás. In: CONGRESSO INTERINSTITUCIONAL BRASILEIRO DE EDUCAÇÃO POPULAR E DO CAMPO CIBEPoC, 2017, p. 94-108.

FERRY, Alexandre da Silva. e NAGEM, Ronaldo Luiz. Analogia \& contra-analogia: um estudo sobre a viabilidade da comparação entre o modelo atômico de Bohr e o sistema solar por meio de um júri simulado. Experiências em Ensino de Ciências, Cuiabá, v. 4, n. 3, p. 43-60, 2009.

FONSECA, Martha Reis Marques da. Química: ensino médio / Martha Reis. 2. ed. São Paulo: Ática, 2016.

FRANCISCO JUNIOR, Wilmo Ernesto. Analogias e situações problematizadoras em aulas de ciências. São Carlos: Pedro \& Editores, 2010.

GENTNER, Dedre. The mechanisms of analogical learning. In: VOSNIADOU, Stella. ORTONY, Andrew. (Eds.). Similarity and analogical reasoning. New York: Cambridge University Press, 1989. p. 199-241.

LISBOA, Julio Cezar Foschini; BRUNI, Aline Thaís; NERY, Ana Luiza Petillo; BIANCO, André Amaral Gonçalves; RODRIGUES, Henrique; SANTINA, Kátia; BEZERRA, Lia Monguilhott; BIANCO, Paulo A. G.; LIEGEL, Rodrigo Marchiori; ÁVILA, Simone Garcia de; YDI, Simone Jaconetti; LOCATELLI, Solange Wagner; AOKI, Vera Lúcia Mitiko. Ser protagonista: Química, v. 1, 3. ed. São Paulo: Edições SM, 2016.

LOPES, Cesar V. M.; MARTINS, Roberto de Andrade. J. J. Thomson e o uso de analogias para explicar os modelos atômicos: o 'pudim de passas' nos livros texto. In: VII ENCONTRO NACIONAL DE PESQUISA EM EDUCAÇÃO EM CIÊNCIAS. Anais. Florianópolis: 2009. Disponível em: http://www.posgrad.fae.ufmg.br/posgrad/viienpec/pdfs/1682.pdf. Acesso em: 05 mai. 20.

MÓL, Gerson de Souza. O uso de analogias no ensino de Química. 1999. 225 f. Brasília: Tese (Doutorado em Química - Universidade de Brasília, Brasília, 1999.

MONTEIRO, Ivone Garcia; JUSTI, Rosária S. Analogias em livros didáticos de química destinados ao ensino médio. Investigações em Ensino de Ciências, Porto Alegre, v. 5, n. 2, 2000 .

MORTIMER, Eduardo Fleury.; MACHADO, Andreia Horta. Química: ensino médio. 3. ed. São Paulo: Scipione, 2016.

MUNARIN, Karla de Oliveira; MUNARIN, Elaine E. de Oliveira. Uma análise crítica das analogias "bola de bilhar", "pudim de passas" e "sistema solar" utilizadas para o ensino de química em modelos atômicos. In: XIV ENCONTRO NACIONAL DE ENSINO DE QUÍMICA, 14. 2008. Anais. Paraná: Universidade Federal do Paraná, 2008. 
NOVAIS, Vera Lúcia Duarte de; ANTUNES, Murilo Tissoni. Vivá: Química: volume 1. Curitiba: Positivo, 2016.

OLIVEIRA, Helena Rivelli. Argumentação no ensino de ciências: o uso de analogias como recurso para a construção do conhecimento. 2012. 130 f. Juiz de Fora: Dissertação (Mestrado em Educação) - Universidade Federal de Juiz de Fora, Juiz de Fora, 2012.

OLIVEIRA, Thaís Machado. Análise das analogias presentes em materiais instrucionais de Química. 2015. 38 f. Viçosa: Trabalho de conclusão de curso (Licenciatura em Química) Universidade Federal de Viçosa, Minas Gerais, 2015.

RAMOS, Tatiana C.; MOZZER, Nilmara. B. Análise do Uso da Analogia com o "Pudim de Passas" Guiado pelo TWA no ensino do Modelo Atômico de Thomson: considerações e recomendações. Química Nova na Escola, São Paulo, v. 40, n. 2, p. 106-115, 2018.

RIBEIRO, Klayton Moreira. Investigação sobre o uso de analogias no ensino de química em Xinguara/PA. 2016. 149 f. Canoas: Dissertação (Mestrado em Ensino de Ciências e Matemática) - Universidade Luterana do Brasil, Canoas, 2016. Disponível em: http://www.ppgecim.ulbra.br/teses/index.php/ppgecim/article/view/261/273. Acessado em 20 abr. 2020.

ROSA, Marcelo D’Aquino. O Programa Nacional do Livro Didático (PNLD) e os livros didáticos de ciências. REPPE: Revista do Programa de Pós-Graduação em Ensino Universidade Estadual do Norte do Paraná Cornélio Procópio, v. 1, n. 2, p. 132-149, 2017.

SANTANA, Isabel Cristina Higino; SANTOS, Francisco Alves; FEITOSA, Edinilza Maria Anastácio; LIMA, Júlio Cesar Teixeira. Analogias, concepções e uso na sala de aula: um estudo de caso acerca do tema. In: XI ENCONTRO NACIONAL DE PESQUISA EM EDUCAÇÃO EM CIÊNCIAS - XI ENPEC. Anais. Florianópolis, 2017.

SANTOS, Wildson Luiz Pereira dos; MÓL, Gerson Souza (coord.). Química cidadã: volume 1. 3. ed. São Paulo: Editora AJS, 2016.

SILVA, Edson Braga; SILVA, Ronaldo Henriques. Curso de Química 2. Ed. Harper \& Row do Brasil, Vila Mariana, SP, 1980.

THIELE, Rodney B.; TREAGUST, David F. An interpretative examination of high school chemistry teachers' analogical explanations. Journal of Research in Science Teaching, v. 31, n. 3, p. 227-242. 1994.

THOMSON, Joseph John. On the structure of the atom: an investigation of the stability and periods of oscillation of a number of corpuscles arranged at equal intervals around the circumference of a circle; with application of the results to the theory of atomic structure. Philosophical Magazine, v. 7, n. 39. p. 237-265, 1904.

Recebido em: 12 de maio de 2020.

Aprovado em: 14 de julho de 2020. 